\title{
Visual impairment and age-related eye diseases in Florida: Findings from 2006 Behavioral Risk Factors Surveillance System (BRFSS) in Nine states
}

This article was published in the following Dove Press journal:

Risk Management and Healthcare Policy

10 September 2009

Number of times this article has been viewed

Yan Li

Amy Z Fan

Lina S Balluz

Behavioral Surveillance Branch, Division of Adult and Community Health, National Center for Chronic

Disease Prevention and Health Promotion, Centers for Disease Control and Prevention, Atlanta, GA, USA
Correspondence: Yan Li

Division for Adult and Community Health, NCCDPHP, Centers for Disease Control and Prevention, 4770 Buford Hwy, NE, MS E-65, Atlanta, GA 3034I, USA

Email yli6@cdc.gov
Purpose: To compare the prevalence of age-related eye disease, visual impairment, and eye care service utilization among adults aged 65 and older in Florida with eight other states.

Methods: In 2006, nine states conducted the visual impairment and access to eye care module using the Behavioral Risk Factors Surveillance System (BRFSS) survey $(\mathrm{N}=62,750)$. Visual impairment was based on self-reported ability to see distant and near objects. Age-related eye diseases including cataract, glaucoma, macular degeneration, and diabetic retinopathy were self-reported with diagnosis confirmed by a health care professional. Eye care visit or examination was assessed by whether a respondent reported an eye visit or dilated eye examination within the past year.

Results: The estimated prevalence of distant and near visual impairment was lower in Florida than in the eight other states (distant: $11.5 \%$ vs $15.2 \%, P<0.001$; near: $22.3 \%$ vs $28.7 \%$, $P<0.001)$. There was no significant difference with the prevalence of age-related macular degeneration and diabetic retinopathy between these two groups. The prevalence of glaucoma and cataract was higher in Florida. The rates of eye care visits $(80.5 \%$ vs $74.8 \%, P<0.01)$ and dilated eye examinations $(74.7 \%$ vs $64.0 \%, P<0.01)$ were higher in Florida. After controlling for demographic variables, chronic conditions, insurance, and eye examination, results for elderly in Florida continued to demonstrate less visually impaired.

Conclusion: Fewer elderly in Florida reported visual impairment in spite of comparable or higher prevalence of age-related eye diseases with other states. Health care utilization and health insurance for eye care coverage were also higher in Florida, which may account for the phenomena. More research is needed to investigate the association.

Keywords: visual impairment, age-related eye disease, eye care service utilization, health insurance, BRFSS

\section{Introduction}

Visual impairment caused by age-related eye diseases affects an estimated 3.3 million people among adults aged 40 years and older in the United States. ${ }^{1}$ This disability is one of the most common public health issues among the elderly because it decreases quality of life by affecting daily living independence, ${ }^{2,3}$ increasing the risk of injury, ${ }^{4,5}$ causing depression and social isolation. ${ }^{6,7}$ The aging of America's population will increase the burden of visual impairment on the society in coming decades.

Florida was ranked in the 1 st place in the proportion of people aged 65 years and older in the United States. ${ }^{8}$ Based on this fact, one might assume the burden of age-related eye disease in Florida would be higher. However, it had long been observed that elderly Floridians demonstrated better health compared with their counterparts 
in other regions across the nation. ${ }^{9,10}$ While many previous estimates on the prevalence of age-related eye diseases were obtained at the national level, ${ }^{11-14}$ few studies conducted were state-based studies. Since elderly Floridians already possessed the reputation of being healthier, we aimed to examine any differences with respect to visual impairment, prevalence of age-related eye disease as well as coverage and utilization of eye care services between Florida and other states across the nation. We also explored the possible reasons for these differences.

\section{Methods}

\section{Data source}

Data for the study were obtained from the Behavioral Risk factor Surveillance System (BRFSS). The BRFSS is a state-based, random-digit dialed ongoing telephone survey of the noninstitutionalized United States civilian population aged $\geq 18$ years. State-specific information about behaviors that are associated with preventable chronic diseases, injuries, and infectious diseases makes the comparison of health behaviors among states possible. ${ }^{15}$ The BRFSS questionnaire includes three parts: the core components, optional modules, and state-added questions. All fifty states and three territories use an identical core questionnaire to conduct the interviews. In addition, states may choose to include optional modules in their data collection, which are sets of questions on various specific topics. ${ }^{15}$

Among the optional modules is the visual impairment and access to eye care module, which collects information regarding the status of visual acuity, eye care service utilization, and professional diagnosis of age-related eye diseases and eye injury. Previous researches have used items in the module to estimate visual impairment at national ${ }^{16}$ and state level. ${ }^{17}$ In 2006, nine states (Arizona, Connecticut, Florida, Georgia, Nebraska, New York, Ohio, Texas, and Tennessee) administered this module. The response rate ranged from $39.8 \%$ to $66.0 \%$ for these states. The questions were asked of respondents aged 40 years and older. However, the current analysis was restricted to people aged 65 years and older in order to compare the interesting variables among the aging population. In this study, Florida had more aging people, with $22.2 \%$ of the population aged 65 years and older versus $16.0 \%$ for the other states.

\section{Variable definitions \\ Vision impairment}

Vision impairment included two questions regarding distant and near vision, respectively: "How much difficulty, if any, do you have in recognizing a friend across the street?" and "How much difficulty, if any, do you have reading print in newspaper, receipts, or numbers?" The response was categorized as "no difficulty", "moderate difficulty", and "extreme difficulty" in descriptive analysis, and was dichotomized as "no difficulty" vs "any extent of difficulty" in the logistic regression analysis. Respondents with "no answer" or "refused to answer" or with the answers "unable to do for other reasons" or "not applicable (blind)" were excluded from analysis.

\section{Age-related eye diseases}

Age-related eye diseases were affirmed by respondents who indicated they "had been told by an eye doctor or other health care professional" that they had cataract, glaucoma, age-related macular degeneration or diabetic retinopathy.

\section{Eye care insurance coverage}

Respondents were classified as not having eye insurance if they answered "no" and as having eye insurance if they answered "yes" to the question, "Do you have any kind of health insurance coverage for eye care?"

\section{Eye care visits in the preceding 12 months and the reasons for not visiting}

Respondents were classified as having visited an eye-care professional "within one year", "more than one year", or "never" based on their answer to the question, "When was the last time you visited any eye-care professional?" The respondents who were classified in the last two categories were also asked the main reason for having not visited. The most cited reasons were "insurance/cost" and "no reason to go". The other reasons were grouped as "others".

\section{Eye examination in the preceding 12 months}

Respondents were classified as having had a dilated eye examination "within one year", "more than one year", or "never" based on their answer to the question "When was the last time you had an eye exam in which the pupils were dilated?"

Other covariates included respondents' demographic (race, gender, marital status) and socioeconomic characteristics (income, education), general health status, and other chronic conditions (coronary heart disease, stroke, diabetes, obesity, activity limitation).

\section{Statistical analysis}

Statistical analyses were performed with SAS (version 9.1; SAS Institute Inc., Cary, NC, USA) and SUDAAN (version 9.0; Research Triangle Institute, Research Triangle Park, NC, USA) to account for the complex sampling design of BRFSS. 
We combined eight states and compared their aggregate data with Florida. Wald chi-squared test was used to compare the differences between Florida and the eight other states on demographics, chronic conditions, age-related eye diseases, and eye care utilization. Multivariate logistic regression was used to examine the differences in the extent of visual impairment (distant and near) between Florida and other states controlling for demographic variables, chronic conditions, insurance, and eye examination.

\section{Results}

Of 62,750 participants for the vision module, 17,269 were aged 65 years and older. Among them, there were 3,261 Florida residents and 14,008 resided in the eight other states. Table 1

Table I Comparison of demographic and health characteristics of adults aged 65 years and older between Florida and eight other states*

\begin{tabular}{|c|c|c|c|c|c|}
\hline & \multicolumn{2}{|c|}{ Florida $(\mathbf{N}=326 \mathrm{I})$} & \multicolumn{2}{|c|}{$\begin{array}{l}\text { Eight other states } \\
(\mathrm{N}=14,008)\end{array}$} & \multirow[t]{2}{*}{$P$ value } \\
\hline & $\%$ & $95 \% \mathrm{Cl}$ & $\%$ & $95 \% \mathrm{Cl}$ & \\
\hline Age (mean) & 74.6 & & 74.6 & & $0.4 I$ \\
\hline Race & & & & & $<0.001$ \\
\hline White & 78.2 & $76.2-80.1$ & 80 & $78.6-81.3$ & \\
\hline Black & 6.3 & $5.3-7.6$ & 8.6 & $7.6-9.6$ & \\
\hline Hispanic & 10.9 & $9.5-12.5$ & 6.4 & $5.6-7.3$ & \\
\hline Other & 4.6 & $3.6-5.7$ & 5.1 & $4.4-5.9$ & \\
\hline Sex & & & & & 0.13 \\
\hline Male & 43.6 & $41.4-45.9$ & 41.5 & $40.0-43.2$ & \\
\hline Female & 56.4 & $54.1-58.7$ & 58.5 & $57.0-60.0$ & \\
\hline Education & & & & & $<0.001$ \\
\hline$<$ High school & 14.5 & $13.0-16.2$ & 16.8 & $15.6-17.9$ & \\
\hline High school & 32.1 & $30.0-34.2$ & 35.1 & $33.7-36.5$ & \\
\hline$>$ High school & 53.4 & $51.5-55.6$ & 47.5 & $46.0-49.0$ & \\
\hline Income & & & & & 0.03 \\
\hline$<\$ 25,000$ & 29.9 & $27.9-32.0$ & 33.0 & $31.6-34.4$ & \\
\hline$\$ 25,000-<\$ 50,000$ & 26.9 & $24.9-28.9$ & 23.8 & $22.6-25.1$ & \\
\hline$\geq \$ 50,000$ & 19.5 & $|7.8-2| .5$ & 19.7 & $18.5-20.9$ & \\
\hline Marital status & & & & & 0.007 \\
\hline Married or partner & 59.3 & $57.2-61.4$ & 56.2 & $54.8-57.6$ & \\
\hline Divorced, separated or widowed & 37.7 & $35.7-39.8$ & 39.6 & $38.2-41.0$ & \\
\hline Never married & 2.8 & $2.2-3.6$ & 3.8 & $3.4-4.3$ & \\
\hline \multicolumn{6}{|l|}{ Age-related eye diseases } \\
\hline Cataract & 56.4 & $54.0-58.6$ & 52.8 & $51.2-54.3$ & 0.02 \\
\hline Glaucoma & 9.9 & $8.6-11.3$ & 10.7 & $9.7-11.8$ & 0.02 \\
\hline Macular degeneration & 8.9 & $7.7-10.4$ & 8.6 & $7.7-9.5$ & 0.56 \\
\hline Diabetic retinopathy & 3.1 & $2.4-4.1$ & 3.7 & $3.1-4.2$ & 0.57 \\
\hline \multicolumn{6}{|l|}{ Other chronic conditions } \\
\hline Diabetes & 18.3 & $16.6-20.1$ & 20.1 & $|9.0-2| .3$ & 0.20 \\
\hline Stroke & 8.1 & $7.0-9.4$ & 8.2 & $7.5-9.1$ & 0.61 \\
\hline Cardiovascular disease & 19.5 & $|7.7-2| .3$ & 21.0 & 19.8-22.2 & 0.11 \\
\hline Activities limit & 29.5 & $27.5-31.6$ & 31.9 & $30.5-33.4$ & 0.02 \\
\hline Obesity & 18.5 & $16.8-20.3$ & 20.8 & $19.6-22.0$ & 0.01 \\
\hline Health status & & & & & $<0.00$ I \\
\hline Excellent/Good & 74.1 & $72.1-76.0$ & 69.4 & $68.0-71.0$ & \\
\hline Fair/Poor & 25.3 & $23.4-27.2$ & 29.7 & $28.3-31.1$ & \\
\hline
\end{tabular}

Notes: *Arizona, Connecticut, Georgia, New York, Nebraska, Ohio, Texas, and Tennessee. 
provides the comparison of demographic and health characteristics among respondents aged 65 years and older between Florida and the eight other states. There was no significant difference on the average of age and proportion of gender between the groups. Compared to their counterparts in the eight other states, the elderly residing in Florida had higher education level (beyond high school), income level (higher in \$25,000-\$50,000 category), more married people, and more Hispanic people. They also reported better health status (excellent/good: 74.1\%) with lower prevalence of activities limit and obesity. Among the age-related eye diseases, the prevalence of cataract and glaucoma was higher in Florida. In contrast, the prevalence of age-related macular degeneration and diabetic retinopathy was comparable with the eight other states.
Table 2 describes vision-related characteristics between Florida and the eight other states. Among respondents aged 65 years and older, fewer Floridians reported visually impaired in both distant and near vision compared to respondents in the other states. The percentage reporting "no difficulty" with distant vision was $84.1 \%$ vs $76.8 \%(P<0.001)$. The percentage of "no difficulty" on near vision was $73.1 \%$ vs $63.0 \%$ ( $P<0.001)$. More Floridians reported having an eye care visit $(80.5 \%$ vs $74.8 \%, P<0.001)$ and dilated eye examination $(74.7 \%$ vs $64.0 \%, P<0.001)$ within one year compared to the other states. The reasons for not having an eye care visit within the past 12 months did not differ between the comparison groups. The rate of health insurance with eye care coverage in Florida was higher (56.2\% vs 50.4\%) than that in the other states.

Table 2 Comparison of age-related eye diseases, visual impairment, eye care service utilization, and insurance of adults aged 65 years and older between Florida and eight other states*

\begin{tabular}{|c|c|c|c|c|c|}
\hline & \multicolumn{2}{|c|}{ Florida $(\mathbf{N}=326 \mathrm{I})$} & \multicolumn{2}{|c|}{$\begin{array}{l}\text { Eight other states } \\
(N=14,008)\end{array}$} & \multirow[t]{2}{*}{$P$ value } \\
\hline & $\%$ & $95 \% \mathrm{Cl}$ & $\%$ & $95 \% \mathrm{Cl}$ & \\
\hline $\begin{array}{l}\text { Difficulty in recognizing } \\
\text { a friend across the street } \\
\text { (distant visual impairment) }\end{array}$ & & & & & $<0.001$ \\
\hline No difficulty & 84.1 & $82.4-85.6$ & 76.8 & $75.5-78.0$ & \\
\hline Moderately difficult & 9.8 & $8.5-11.2$ & 13.0 & $|2.0-| 4 . \mid$ & \\
\hline Extremely difficult & 1.7 & $1.2-2.3$ & 2.2 & I.8-2.7 & \\
\hline $\begin{array}{l}\text { Difficulty in reading print } \\
\text { in newspaper, receipt or numbers } \\
\text { (near visual impairment) }\end{array}$ & & & & & $<0.001$ \\
\hline No difficulty & 73.1 & 7I.I-75.I & 63.0 & $61.6-64.5$ & \\
\hline Moderately difficult & 19.5 & $|7.7-2| .3$ & 25.3 & $24.0-26.7$ & \\
\hline Extremely difficult & 2.8 & $2.2-3.7$ & 3.4 & $3.0-4.0$ & \\
\hline Last time of visiting eye doctor & & & & & $<0.001$ \\
\hline$<12$ months & 80.5 & $78.5-82.3$ & 74.8 & $73.4-76.1$ & \\
\hline One or more years & 19.0 & $17.2-20.9$ & 24.2 & $22.9-25.6$ & \\
\hline Never & 0.6 & $0.2-1.4$ & 0.2 & $0.1-0.3$ & \\
\hline $\begin{array}{l}\text { Reasons for no eye care visits } \\
\text { within the last } 12 \text { months }\end{array}$ & & & & & 0.51 \\
\hline Cost/insurance & 11.5 & $8.4-15.6$ & 12.6 & $10.6-14.8$ & \\
\hline No reason to go & 54.8 & $49.5-60.1$ & 54.3 & $51.1-57.3$ & \\
\hline Others & 30.0 & $25.4-35.1$ & 30.9 & $28.1-33.9$ & \\
\hline $\begin{array}{l}\text { Last time of dilated eye } \\
\text { examination }\end{array}$ & & & & & $<0.001$ \\
\hline$<12$ months & 74.7 & $72.4-76.9$ & 64.0 & $62.3-65.6$ & \\
\hline One or more years & 22.7 & $20.6-24.9$ & 29.1 & $27.5-30.7$ & \\
\hline Never & 2.6 & $1.8-3.8$ & 3.6 & $3.1-4.2$ & \\
\hline If having health insurance with eye & & & & & \\
\hline care coverage & 56.2 & $53.9-58.5$ & 50.4 & $48.9-52.0$ & 0.01 \\
\hline
\end{tabular}

Notes: *Arizona, Connecticut, Georgia, New York, Nebraska, Ohio, Texas, and Tennessee. 
Table 3 The association of health insurance with eye care coverage and eye care service utilization among adults aged 65 years and older for nine states*

\begin{tabular}{|c|c|c|c|}
\hline & \multicolumn{3}{|c|}{$\begin{array}{l}\text { If having health insurance with eye care } \\
\text { coverage }\end{array}$} \\
\hline & Yes \% $(95 \% \mathrm{Cl})$ & No\% $(95 \% \mathrm{Cl})$ & $P$ value \\
\hline $\begin{array}{l}\text { Last time of eye } \\
\text { doctor visit }\end{array}$ & & & $<0.001$ \\
\hline$<12$ months & $82.9(81.6-84.4)$ & $70.4(68.6-72.1)$ & \\
\hline One or more years & $17.0(15.6-18.4)$ & $29.1(27.5-30.9)$ & \\
\hline Never & $0.1(0.0 \mathrm{I}-0.2)$ & $0.5(0.3-0.9)$ & \\
\hline Total & 1.00 & 1.00 & \\
\hline $\begin{array}{l}\text { Last time of dilated } \\
\text { eye examination }\end{array}$ & & & $<0.001$ \\
\hline$<12$ months & $75.6(73.8-77.4)$ & $61.7(59.6-63.7)$ & \\
\hline One or more years & $21.9(20.2-23.7)$ & $34.2(32.2-36.3)$ & \\
\hline Never & $2.5(2.0-3.1)$ & $4.1(3.4-5.0)$ & \\
\hline Total & 1.00 & 1.00 & \\
\hline
\end{tabular}

Notes: *Arizona, Florida, Connecticut, Georgia, New York, Nebraska, Ohio, Texas, and Tennessee.

$* * 95 \%$, confidence interval.

Because there existed the same pattern of association between health insurance coverage and eye care utilization, we combined the data from all nine states to examine the overall association. The results showed that people with health insurance covering eye care were associated with a higher percentage of eye care visit $(82.9 \%$ vs $70.4 \%$, $P<0.001)$ and dilated eye examination $(75.4 \%$ vs $61.5 \%$, $P<0.001)$ within a year.

The results from multivariate logistic regressions are showed in Table 4. Distant and near visual impairment were treated as different outcomes in the model. Residential setting was a strong predictor for both distant and near visual impairment, ie, elderly who lived in Florida were less likely to report distant (odds ratio [OR]: $0.68,0.57-0.81$ ) and near (OR: 0.66, 0.58-0.76) visual impairment. We further controlled for demographic variables including race, income, education and marital status, all of which had different distribution between the comparison groups, in Model 1. The adjusted odds ratio (AOR) did not change. Further controlling for health status in Model 2 and further controlling for health insurance, eye care visit and exam in Model 3 also had little influence on the AOR.

\section{Discussion}

Our study showed Florida had larger proportion of senior population, and its prevalence of age-related eye diseases was comparable to or higher than the eight other states. However, Floridian elderly reported better distant and near visual function compared to their peers in the eight other states, even though all considered factors were accounted for. Some researchers had demonstrated that Florida's elderly were in much better health than the elderly in other areas of the country: The age-sex-standardized mortality rate for whites aged 65-84 years in Florida was 10\% below the US average in $1989-1991,{ }^{10}$ and the elderly population had proportionally fewer elderly individuals require/eligible for nursing home admission. ${ }^{8}$ The results of current study provided additional evidence that Florida seniors also reported better visual function than the elderly in other regions.

Migration is defined as a change in one's usual place of residence. ${ }^{18}$ Because Florida has long been the leading destination for elderly permanent migrants, ${ }^{19}$ the aging population in Florida increases mainly due to migration rather than from natural aging of Florida's population. ${ }^{20}$ Smith and colleagues conducted a survey in Florida and demonstrated that higher income and education, higher proportion of married, better health status, and lower proportion of employment were associated with the higher probability of in-migration. ${ }^{18}$ Other researches also reported that Florida migrants were

Table 4 Multivariate analysis for distant and near visual impairment: Florida versus eight other states

\begin{tabular}{|c|c|c|c|c|}
\hline & & Florida & Other states* & $P$ value \\
\hline & & \multicolumn{3}{|l|}{$\overline{\text { AOR }(95 \% \mathrm{Cl})}$} \\
\hline \multirow[t]{3}{*}{ Distant visual impairment } & Model I' & $0.68(0.57-0.8 \mathrm{I})$ & 1.00 & $<0.001$ \\
\hline & Model $2^{2}$ & $0.69(0.58-0.83)$ & 1.00 & $<0.001$ \\
\hline & Model $3^{3}$ & $0.61(0.50-0.75)$ & 1.00 & $<0.001$ \\
\hline \multirow[t]{3}{*}{ Near visual impairment } & Model I' & $0.66(0.58-0.76)$ & 1.00 & $<0.001$ \\
\hline & Model $2^{2}$ & $0.67(0.58-0.77)$ & 1.00 & $<0.001$ \\
\hline & Model $3^{3}$ & $0.66(0.57-0.77)$ & 1.00 & $<0.001$ \\
\hline
\end{tabular}

Notes: *Arizona, Connecticut, Georgia, New York, Nebraska, Ohio, Texas, and Tennessee. 'Adjusted for race, income, education and marital status; ${ }^{2}$ Further adjusted for health status; ${ }^{3}$ Further adjusted for health insurance, eye care visit, and exam.

Abbreviations: $\mathrm{AOR}$, adjusted odds ratio; $\mathrm{Cl}$, confidence interval. 
younger, had intact marriage, ${ }^{21}$ and lower stroke mortality rate. ${ }^{22}$ Although information on migration was not available in BRFSS, our results showed Floridian elderly had a better profile on the above variables. Our study sample may consist of more in-migrants, who are healthier, wealthier and better-educated. This could play a role contributing to a better visual function of Floridian seniors.

The nature of cross-section of our study leaves it open whether people with more severe eye disease tend to see health care providers more frequently or careful monitoring of eye health and regular eye examinations can help to detect and treat eye diseases in their early stage. However, we found that elderly Floridians had more frequent eye care visit and dilated eye exam while they reported better visual function. This resonates with a previous report that the elderly residents of Florida used more medical care. ${ }^{10}$ Many follow-up studies have found that the proportion with visual impairment was lower among people who used eye care services on a regular basis than those who had not, and recommended early screening among high risk population to prevent avoidable causes of vision loss. ${ }^{23-25}$ Our results, along with those of previous studies, suggest that using more eye care may improve eye health condition.

The association between health insurance coverage and eye care utilization found in this study also helped to explain why Floridian seniors were motivated to use more eye care services. Floridian elderly had significantly higher insurance coverage than the other states. Moreover, nearly one third of Florida's hospitals offer comprehensive geriatric assessment services and about a quarter are treating increasingly higher concentrations of Medicare patients. ${ }^{26}$ Abundant free advice on nutrition, health, and benefit claims are available in hospitals and senior centers. ${ }^{20}$ The state's elderly friendly health care system and policies with a focus on health education and disease prevention in Florida induced more utilization of health care.

Aside from typical limitations such as the landline coverage bias, self-report data, and cross-section design that BRFSS may have, this study is subject to several additional ones. First, the vision module was only conducted in nine states in 2006, thus the comparison within these states may not be generalizable to all states in the US. Second, people with early stage of age-related eye diseases may not have an obvious symptom and thus may not have a clear professional diagnosis. Third, the question on retinopathy was asked among diabetic patients. The information of other types of retinopathy caused by such conditions as hypertension or central retinal vein occlusion was not available in this survey.
Finally, refractive error had been identified as one of the leading causes of visual impairment in US. ${ }^{27}$ BRFSS did not ask about use of spectacles, thus we did not take refractive error into account for visual impairment. Better reported visual function in Florida may be attributed to higher rate of visual acuity correction.

In conclusion, although Florida has higher proportion of older adults and its prevalence of age-related eye diseases were comparable with or higher than the eight other states, Floridian elderly reported much better visual function. It may result from their better health, socioeconomic status, more utilization of eye care services, as well as migration to a state such as Florida where policies and services promote senior health. A better understanding of these factors is necessary for future development and implementation of effective health policies and intervention programs that address eye-care demands among an elderly population.

\section{Disclosures}

The findings and conclusions in this report are those of the author(s) and do not necessarily represent the official position of the Centers for Disease Control and Prevention. The authors report no conflicts of interest in this work.

\section{References}

1. National Eye Institute. Prevalence of blindness and low vision among adults aged 40 years and older in the United States. Bethesda, MD: National Eye Institute; 2004. Available from http://www.nei.nih.gov/ eyedata/pbd_tables.asp. Accessed on August 10, 2009.

2. Keeffe JE, Jin CF, Weih LM, McCarty CA, Taylor HR. Vision impairment and older drivers: who's driving? Br J Ophthalmol. 2002;86(10):1118-1121.

3. Frost A, Eachus J, Sparrow J, et al. Vision-related quality of life impairment in an elderly UK population: associations with age, sex, social class and material deprivation. Eye. 2001;15(Pt 6):739-744.

4. Roberts I, Norton R. Sensory deficit and the risk of pedestrian injury. Inj Prev. 1995;1(1):12-14.

5. Ivers RQ, Cumming RG, Mitchell P, Simpson JM, Peduto AJ. Visual risk factors for hip fracture in older people. J Am Geriatr Soc. 2003;51(3):356-363.

6. Tsai SY, Cheng CY, Hsu WM, Su TP, Liu JH, Chou P. Association between visual impairment and depression in the elderly. $J$ Formos Med Assoc. 2003;102(2):86-90.

7. Lamoureux EL, Fenwick E, Moore K, Klaic M, Borschmann K, Hill K. Impact of the severity distance and near vision impairment on depression and vision-specific quality of life in older people living in residential care. Invest Ophthalmol Vis Sci. 2009;50(9):4103-4109.

8. Street D. Florida's aging population: Critical Issues for Florida's Future. Tallahassee, FL: Pepper Institute on Aging and Public Policy: 2007.

9. Skinner J, Wennberg JE. Exceptionalism or extravagance? What's different about health care in South Florida. Health Aff (Millwood). 2003; Suppl Web Exclusives:W3-372-375.

10. Fuchs VR. Floridian exceptionalism. Health Aff (Millwood). 2003; Suppl Web Exclusives:W3-357-362.

11. Congdon N, Vingerling JR, Klein BE, et al. Prevalence of cataract and pseudophakia/aphakia among adults in the United States. Arch Ophthalmol. 2004;122(4):487-494. 
12. Friedman DS, O'Colmain BJ, Munoz B, et al. Prevalence of age-related macular degeneration in the United States. Arch Ophthalmol. 2004;122(4):564-572.

13. Friedman DS, Wolfs RC, O'Colmain BJ, et al; Eye Diseases Prevalence Research Group. Prevalence of open-angle glaucoma among adults in the United States. Arch Ophthalmol. 2004;122(4):532-538.

14. Kempen JH, O'Colmain BJ, Leske MC, et al. The prevalence of diabetic retinopathy among adults in the United States. Arch Ophthalmol. 2004;122(4):552-563.

15. Centers for Disease Control and Prevention (US). Behavioral Risk Factor Surveillance System Users 'Guide. Atlanta, GA: US Department of Health and Human Services, Centers for Disease Control and Prevention; 1998.

16. Saaddine JB, Narayan KM, Engelgau MM, Aubert RE, Klein R, Beckles GL. Prevalence of self-rated visual impairment among adults with diabetes. Am J Public Health. 1999;89(8):1200-1205.

17. Bailey RN, Indian RW, Zhang X, Geiss LS, Duenas MR, Saaddine JB Visual impairment and eye care among older adults - five States, 2005 MMWR Morb Mortal Wkly Rep. 2006;55(49):1321-1325.

18. Smith SK, House M. Snowbirds, sunbirds, and stayers: seasonal migration of elderly adults in Florida. J Gerontol B Psychol Sci Soc Sci. 2006;61(5):S232-S239.
19. Longino CF Jr, Bradley DE. A first look at retirement migration trends in 2000. Gerontologist. 2003;43(6):904-907.

20. Beck B. The perfect sunset. The Economist. 1996;338(7950):14-16.

21. Litwak E, Longino CF Jr. Migration patterns among the elderly: a developmental perspective. Gerontologist. 1987;27(3):266-272.

22. Lanska DJ, Peterson PM. Effects of interstate migration on the geographic distribution of stroke mortality in the United States. Stroke. 1995;26(4):554-561.

23. Muller A, Keeffe JE, Taylor HR. Changes in eye care utilization following an eye health promotion campaign. Clin Experiment Ophthalmol. 2007;35(4):305-309.

24. Tay T, Rochtchina E, Mitchell P, Lindley R, Wang JJ. Eye care service utilization in older people seeking aged care. Clin Experiment Ophthalmol. 2006;34(2):141-145.

25. Bylsma GW, Le A, Mukesh BN, Taylor HR, McCarty CA. Utilization of eye care services by Victorians likely to benefit from eye care. Clin Experiment Ophthalmol. 2004;32(6):573-577.

26. Sherer JL. Age wave. Florida learns from geriatric care. Hosp Health Netw. 1993;67(15):48-52.

27. Congdon N, O'Colmain B, Klaver CC, et al. Causes and prevalence of visual impairment among adults in the United States. Arch Ophthalmol. 2004;122(4):477-485.
Risk Management and Healthcare Policy

\section{Publish your work in this journal}

Risk Management and Healthcare Policy is an international, peerreviewed, open access journal focusing on all aspects of public health, policy, and preventative measures to promote good health and improve morbidity and mortality in the population. The journal welcomes submitted papers covering original research, basic science, clinical \& epidemio-

\section{Dovepress}

logical studies, reviews and evaluations, guidelines, expert opinion and commentary, case reports and extended reports. The manuscript management system is completely online and includes a very quick and fair peerreview system, which is all easy to use. Visit http://www.dovepress.com/ testimonials.php to read real quotes from published authors. 